\title{
When West meets East: The case of a Scandinavian consulting firm's expansion into India
}

Flemming Poulfelt, Irene Skovgaard Smith and Kåre Groes Christiansen

\begin{abstract}
The paper explores how a Scandinavian management consulting firm entered the Indian market and how this process of international expansion set in motion a significant change in organisational identity. The purpose of the article is to explore and reflect on how a medium-sized consulting firm managed its transition to the new context of India and the resulting implications for practising consulting in a new environment. In this case, the experience in India changed the firm and challenged preconceptions about the process of globalisation being a one-way export of Western products, knowledge and ideas. A different firm emerged from the experience: one that is not only more international but which is also now becoming more clearly differentiated in the Scandinavian market. The phenomenon observed is termed 'reverse consulting' and is emerging as a new driver in the internationalisation of professional services firms.
\end{abstract}

\section{Keywords:}

management consulting firm; internationalisation; international management; entry strategy; professional service firm; reverse consulting; organisational identity; integration process.

\section{Reference:}

Poulfelt, F., Smith, I.S. and Christiansen, K. (2014) When West meets East: the case of a Scandinavian consulting firm’s expansion into India, European Journal of International Management, Vol. 8, No. 4, pp.373-391. 


\section{Introduction}

Management consulting is a global business and remains a booming business. Although the crisis in the years 2008-2010 dampened the growth rates experienced in previous years, prospects for a recovery for the business have more recently become evident in the form of new optimism and growth (Source Information Services, 2011). It is estimated that total management consulting revenues in 2010 exceeded $\$ 300$ billion, and the future looks promising with further growth expected. Among the key drivers for this development are (a) an increased complexity in business; (b) new emergent markets; (c) emphasis on outsourcing and offshoring; (d) changes driven by technology and deregulation and (e) major reforms in the public sector.

When consulting as a business really took off after the Second World War, firms tended to focus on domestic markets (McKenna, 1995). This pattern has since changed dramatically and a fairly large part of the business today is global in terms of revenues, clients and consultants. The major trigger for the growing internationalisation in the consulting industry was the post-WW2 period. As a part of the Marshall Plan, American manufacturing companies started to expand their operations abroad by exporting to Europe and setting up subsidiaries on the continent. Selling American management know-how to eager European managers was what J.J. Servan-Schreiber labelled The American Challenge (McKenna, 1995).

As an extension of this activity, consulting firms started to move across to Europe with their clients. When McKinsey \& Co. entered Europe back in 1950s for example, it was because it wanted to follow its clients, capitalise on Marshall Aid as well as explore new opportunities - which the then managing partner Marvin Bower called 'geographic entrepreneurialism’ (Berry, 1988). Some 1970 US firms worked in or established offices in Europe. As Nees (1986) concluded, 'More and more management consulting businesses are moving their business abroad - so many in fact that the consulting industry has become quite international'. 
Over the years many consulting firms have expanded globally and transformed their practices from a national platform to an international presence on many continents, as has been the case with the large global consulting firms (Curnow and Reuvid, 2001; Rhinesmith, 2009). However, the established global players are not the only ones that have embarked on the journey of internationalising their practices. An abundance of firms of various sizes, across nations and type of businesses have expended considerable resources and much energy in their attempt to enter and succeed in the international arena.

For many the road has been bumpy, as expanding a business across borders often is more complicated and demanding than first expected (Baden-Fuller, 1994). Variances in culture and traditions can affect cooperation between different countries. Knowledge-sharing and transfer is more complicated in an international context for example (Werr and Sternberg, 2003; Hitt et al., 2006). The goals of achieving economies of scale have also proven more difficult than anticipated, with a detrimental effect on profitability for a number of consulting firms. Company size can be a factor here, as studies show that size is important for success in international markets (Winch, 2008). Then there is the issue of trust, something an incoming professional service firm must establish from scratch if it has not previously had a presence in a given market. Overcoming obstacles here has also been a challenge for many firms (Rogers and Tierney, 2004).

Today there is a (new) drive to internationalise as a number of major national firms with some regional presence expand their operations to be able to support their clients - as they themselves move further away and outsource or off-shore various activities. Examples include European consulting firms moving to China or India to support their clients in the sourcing activities they are embarking on.

\subsection{Purpose and assumptions}


The purpose of the paper is to explore and understand how a Scandinavian Tier 2 consulting firm, Valcon A/S, managed its transition to the new environment of India, and determine the implications for the internationalisation of consulting service businesses more generally. This paper and the analysis within it are based on a number of assumptions. First, it is assumed that the classic type of entry strategy must be rethought given that consulting is a service business and the resources to be deployed are limited in both financial and human capital terms. This means that consulting firms need to consider alternative ways of setting up a new practice compared with the traditional models of internationalisation (as for instance illustrated in the Uppsala model (Johanson and Wiedersheim-Paul, 1975; Johanson and Vahlne, 1977) or the internationalisation model of Multinational Corporations (MNCs) as suggested by Pearlmutter (1969).)

Secondly, it is assumed that the practice of consulting and the processes involved need to be reconsidered in an Eastern context, given that a major driver in consulting is the contextual setting (Jacoby Petersen and Poulfelt, 2002). Here, the idea of 'reverse consulting' will be explored as a new way of approaching consulting - instead of merely trying to impose a Western/Scandinavian model. Moving away from the traditional focus on the West leading the East and instead exploring how integrated, mutually beneficial approaches can be developed and utilised, might also inspire and change Western management and consulting models.

Thirdly, it is assumed that the internationalisation of a domestic consulting firm's practice will have major implications for its own organisational culture and identity. An extraordinary event in a firm's history, such as Valcon's entry into India and the changes involved, is likely to prompt intensified identity work (Jenkins, 2004). Such an event, which represents both rupture and an encounter with cultural 'others', triggers key identification processes concerning who 'we' are and the extent to which 'we' are both similar to and different from other consulting firms. 


\section{Theories of internationalisation}

For more than 30 years there has been a widespread effort in research on internationalisation processes in general and strategic modes of entry into new markets more specifically. Various approaches to export and internationalisation have been proposed and applied. These range from theories (or schools) and models assuming a traditional way of expanding the activities of a company - as for instance portrayed in the Uppsala School (Johanson and Wiedersheim-Paul, 1975; Johanson and Vahlne, 1977) - and the network approach (Johanson and Mattson, 1988), to models taking a more radical approach - such as the 'born global concept’ proposition (McKinsey \& Co, 1993).

The Uppsala framework focuses on acquisition and learning. Central issues concern how organisations learn and how this learning affects their subsequent investment behaviour. Among the assumptions is that firms start (and continue to) invest in one or a few neighbouring countries rather than investing in distant markets and/or several markets simultaneously. 'Closer' markets are those that are perceived to be not too far removed culturally - i.e. markets in which the extent of knowledge and the 'comfort level' are higher. When a certain comfort level in a particular market has been achieved, an additional geographical expansion can take place. This model indicates a ripple effect. The 'network' approach can be seen as a rephrasing of the Uppsala model, using similar concepts but trying to explain international behaviour by placing a company within a multilateral framework - one that mobilises the relationships on an intraorganisational and inter-organisational basis. The philosophy is that the establishment of, say, commercial and financial relations with other players in the network makes it possible for firms to extend their connections and gradually widen their territory to become international. The network model can perceived as a way to capitalise on the social capital of firms and people.

The third model of internationalisation was introduced by Pearlmutter (1969) and comprises a scheme for categorising multinational corporations' internationalisation processes as ethnocentric, polycentric or geocentric in orientation. 'Ethnocentric' refers to a company's instinctive orientation 
towards its home market in the way it approaches internationalisation, i.e. 'the way we do business at home is the way to do it everywhere'.

'Polycentric' goes to the other extreme, with orientation towards the host country and the emphasis on localisation above all else. A ‘geocentric’ perspective meanwhile means looking outward at the whole world and moving towards global integration. Pearlmutter's interest was in how multinationals develop a global mindset and behaviour accordingly.

A further, fourth perspective is the 'born global' mode. This approach, when it was launched in the early 1990s, applied in particular to new international ventures and global start-ups. It assumes: (a) that small is beautiful and (b) that a gradual approach to internationalisation is no longer relevant (Cavusgil, 1994). Companies with a 'born global' mindset tend to see the world as one large market.

However none of these models fully captures the way that the featured firm, Valcon, has approached internationalisation and its entry strategy into India, as will become evident. Rather Valcon has combined a process of 'leapfrogging', whereby a firm bypasses stages in the classical model (Hedlund and Kverneland, 1985) by way of a ‘big step’ approach - where international expansion is embarked on not as a gradual, incremental process but rather as a discontinuous process characterised by big moves (Pedersen and Shaver, 2011). We will see too that Valcon's journey also draws on elements from each of the ethnocentric, polycentric and geocentric orientation models. To home in on specific entry strategies, these are often described in terms of complexity and involvement, ranging from exporting, licensing, franchising, strategic alliance, joint ventures, M\&A and management contracts to setting up a subsidiary (or opening an office). In this regard Valcon has subscribed to a modified version of the last option in the way it followed one of its clients to India. Looking more specifically at strategies for developing an international presence in professional services, it soon becomes clear that the literature is fairly sparse and limited. Most related sources cover the knowledge base of the firm (Robertson, Scarborough, 2003), loyalty among clients (Frantz 
and McDougell, 2004); various human capital issues (Rogers and Tierney, 2004, Hitt et al., 2006); reputation management (Zabala et al., 2005) and trust and control issues (Rogers and Tierney, 2004) - while a few focus on main obstacles to entering new markets (Freeman and Sandwell, 2008). With this case study we are thus adding to and extending the empirical basis for further theorising on the internationalisation of professional service firms. The theoretical frame of this paper is based on a combination of various schools of thought about internationalisation, while highlighting the specific challenges facing Valcon and lessons that can be learnt from the way it set about establishing a new operation in India.

\section{Setting the scene}

Internationalisation within consulting was first witnessed in the early 1950s. A global segmentation process has also taken place over the years, with the result that the management consulting industry today can be classified according to the following tiers when it comes to internationalisation (Greiner and Poulfelt, 2009):

Tier 1: The major global consulting firms (e.g., McKinsey, BCG, Booz Allen, A.T Kearney, IBM Consulting, Cap Gemini and Accenture);

Tier 2: Major national firms with some regional presence;

Tier 3: Small and medium sized national consulting firms with limited or no international outlook.

Tier 1 firms and the large global firms have been operating on the global scene for a good many years. Other consulting firms, categorised as Tier 2 organisations, traditionally have been operating more regionally (for instance within Scandinavia, Europe or Asia), while Tier 3 firms have been carrying out domestic consulting work. Today, in an emerging trend, some of the Tier 2 firms are now expanding their operations in order to be able to support their clients as they themselves expand 
globally. Our case firm, Valcon, belongs to this group of Tier 2 firms. Given this background, establishing a new office 4000 miles away in a totally different business context was a big leap.

\subsection{The Indian management consulting market}

The Indian consulting industry has been growing at a fast pace in recent years. In total the Asia Pacific consulting industry generated $\$ 33.5$ billion of revenues in 2008 and is expected to reach 39.2 billion by 2012, a CAGR of 4\% (Consultgenie, 2009). Of the total revenues, India represents $5.4 \%$, equal to \$18 billion in 2008 and \$21.2 billion in 2012.

Compared with some of the other Asian consulting markets such as Japan and China, the Indian market is still immature. Among the services offered, corporate strategy, outsourcing services, human resource management and operations management have been some of the prominent disciplines. Within the strategy field, the big and established players command close to threequarters of the market, leaving only a small share for upcoming firms.

The largest concentration of consultancy organisations is in the four metropolitan cities. Delhi (accounting for 25.7\%) has the highest number of firms, followed by Mumbai (25.5\%), Chennai (12.1\%) and Calcutta (9.1\%). The main driver for consulting services has been the maturity of Indian industry. This has driven the expansion of the consulting industry not only in terms of size, but also in terms of service offerings. In addition, specialist consulting advice has being sought by clients in India, creating an opportunity for a number of niche organisations to exploit their specific knowledge bases and resources (Rathore, 2010).

The Indian consulting market is characterised by tough competition, and today it is more or less a buyers’ market. The playing field is primarily comprised of the big global players and an abundance of local firms of various sizes. When it comes to other firms with representation in India, the number is fairly limited and European firms in particular are scarce. 
The major strengths of Indian consulting organisations include professional competence, the low-cost structure, diverse capabilities, high adaptability and the quick learning capability of Indian consultants. By contrast the major weaknesses, which have hindered the export growth of consulting sector in the country, are low quality assurance, low local presence overseas, a low equity base, a lack of market intelligence and a low level of R\&D (Rathore, 2010). It was in this business environment that the Danish consultancy Valcon decided to establish a new operation in India.

\section{Internationalisation in practice - a case study}

The following empirical analysis is based on a single case study (Yin, 2003), conducted primarily through participant-observation by the third author who is a managing partner in the consulting firm (Valcon A/S) and had a key role in the establishment of consulting activities in India. He thus experienced the entire process first-hand and had access to relevant documentary information. As authors, we held a number of workshops in which we mapped the journey of Valcon to identify key issues of importance in the internationalisation process. In addition, one author conducted several follow-up interviews with both the client and the consulting firm. The case study is designed to present an in-depth empirical description of the relatively unexplored and context- specific phenomenon of the internationalisation of Tier 2 consulting firms.

Case study research is a qualitative approach in which a bounded system (a given case) is explored over time in its real-life context (Yin, 2003) in order to increase our understanding of a specific phenomenon. Material and data cited in case studies may be derived from multiple sources including participant-observation, documentary information and interviews (Yin 2003) - the primary sources of data in our case study. According to Yin, the strength of using participant-observation is related to the fact that events are followed and experienced in real time and in context. This kind of study can also provide valuable insight into interpersonal behaviour and motives, because the researcher is also a participant in the events under study. The strength of documentary sources (such 
as emails and other written communication, minutes from meetings, reports, etc.) on the other hand benefits from its stable and unobstructive character, its potentially broad coverage and its detail and exactness (Yin, 2003).

A distinctive feature of our case study is the extensive level of access, which only a full participant in the role as key decision-maker could have achieved in this organisational setting. The follow-up interviews conducted by the first author serve as important complementary data on the internationalisation process, seen from other perspectives in both the client organisation and the consulting firm.

The case analysis in the section below is interpretive and phenomenological in nature. As such, it seeks to describe rather than explain, with the aim of increasing our understanding of the phenomenon of the internationalisation of Tier 2 consulting firms. The case analysis is thus an interpretive exploration of the internationalisation process the case firm went through and how it was experienced. The analysis is structured around empirical themes identified in the case material and combines description (based on participant observation and interviews) with interpretation.

\section{Case analysis}

The case firm, Valcon (www.valcon.dk), is a Scandinavian consulting firm with offices in Denmark, Sweden and Norway and international offices in the Czech Republic, India and China. Valcon employs more than 150 people. Value creation is the cornerstone of the firm. The specialist competencies and experience of the consultants lay the foundation for creating solutions that work and ensure innovation and added value for the clients.

Over the following sections we explore Valcon's entry and work in India for Danish subsidiaries and local companies. The analysis is organised according to four main themes identified in the case study. Each section is concluded with a discussion of each theme in relation to the 
existing literature referenced above, and in terms of what we can learn from Valcon's specific experiences in India.

\subsection{Client pull for internationalisation - entering the Indian consulting market}

Expanding the Valcon business outside Scandinavia was a topic that had often been discussed at Valcon, as clients were increasingly establishing operations abroad. Several clients were sourcing work in China and setting up manufacturing plants there. The most advanced of them had also begun outsourcing white-collar work to India.

The dilemma for Valcon was obvious. How could it advise clients on the internationalisation process if they had not been through it themselves? The challenge was not answering the question ‘why', since significant market potential and cost advantage in both China and India made internationalisation look inherently attractive. The real challenge was 'how' - i.e. how to explore the market potential and benefit from the cost advantages. Finding answers to the 'how' a question was not easy, but it was clear that Valcon could not provide real value to its clients without a deeper understanding of China and India. Simply facilitating strategy projects would not be sufficient. Nor would be advice based on Google research. Hands-on experience was needed.

Valcon knew that starting up from scratch, in a new and very different market without clients would be difficult. Its previous expansion into the Swedish market had provided a valuable lesson in this regard. Instead Valcon waited for a chance to follow a client. This came in the form of a large global engineering company headquartered in Denmark. Valcon had been working for this client for some years already with the aim of helping it streamline its Danish engineering operations. The client's strategy was that a significant part (80\%) of its engineering work should be carried out in India. To this end it had established a large engineering centre in the country to support the project centres in Europe and the USA. 
The work to be carried out in India became part of the global engineering processes. As expressed by the client in an interview, it was a logical step to ask Valcon to follow the company to India as Valcon had trained the Danish organisation in process optimisation and Lean thinking. It was important for the client too that Valcon's methods and techniques were sufficiently localised and that it could offer its services at local rates. As a result of these concerns an open discussion with the client in both Denmark and India ensued and it was agreed that the best option was for Valcon to set up a legal company in India and build a consulting team. The client offered to help Valcon establish its operations in India, and also hosted the consultants in its offices initially. Both the client and Valcon found this solution optimal. They got started quickly and were able to have localised Valcon services at an Indian cost level yet with Valcon's level of quality. As the client put it, “It was a win-win situation. We got accessibility and uniform offerings, and Valcon got a foothold in the Indian market in a fairly uncomplicated way”. (Client interview)

Reflecting on Valcon's process of entering the Indian consulting market, it is interesting to note the decisive role one particular client played in creating the pull that prompted Valcon to start up in India, and how. As the client put it at the time, 'We have been listening to you [the consultants] for years about the necessity of following the clients. Now you have to walk the talk'. Valcon is still working for the same client in India, but has since expanded its operations with a growing base of both Indian and international clients and now has its own local premises.

The proactive approach and involvement of a client allowed Valcon to skip stages in the classic internationalisation model (Hedlund and Kverneland, 1985) and enter a market which to all intents and purposes was outside of its comfort zone. The client concerned not only prompted Valcon to enter the Indian consulting market, but also offered to take on significant responsibilities in the development of Valcon as its Indian consultancy supplier. The client wanted a local provider with Valcon's specific mindset and approach, but also a service delivered by Indian consultants and at local cost level. With reference to Pearlmutter's framework (1969) this encompasses elements of 
both an ethnocentric and a polycentric orientation: ethnocentric in terms of the focus on exporting Valcon’s 'home’ approach and mindset to India; but polycentric in its simultaneous approach to localisation and recruitment of local Indian consultants.

Valcon’s entry strategy thus bore the hallmarks of a ‘big step’ (Pedersen and Shaver, 2011) in that the firm set up a subsidiary and recruited and developed local talent in India. It did this by way of a rare partnership with a client, which set the agenda for Valcon's internationalisation in significant ways. This also echoes the network approach to internationalisation (Johanson and Mattson, 1988) - as it was the close relationship with a client, and access to that client's resources, that made the move possible.

The insistence on localisation by the client meant that the logic of internationalisation, as a process of simply exporting Western consulting services to emerging economies, was turned on its head. It evolved to represent an integrated approach, which was essentially both Scandinavian and Indian in nature. This point will be discussed further in the next sections.

\section{2 'Coming of age' in India - learning to compete for talent by re-imagining Valcon}

The third author of this paper is the Valcon partner who went to India to initiate the recruitment of local consultants. The recruitment process began in the classic way, by defining the required profiles and asking the recruiting company to suggest candidates. When Valcon embarked on the interview process, it quickly learnt a couple of important lessons. First, it was no problem to identify extremely qualified prospective employees who were born and educated in India and who had the necessary global profiles, with work experience in international companies. Interviews were carried out with candidates who had years of extensive experience of setting up plants and building supply chains for companies like Toyota, Ford, Nokia and Saint Gobain. However, Valcon also realised that competition for this talent was fierce. In Scandinavia Valcon is a well-known brand, which means that it is the new recruits who have to 'sell' their competences to Valcon; recruitment in Denmark is 
a buyers' market for the firm. In India, the roles were reversed. Here, Valcon had to sell itself to potential candidates, which was a new experience. This meant being able to formulate an answer to the question 'What can Valcon do for India' and not merely 'What can Valcon do for Scandinavian companies in India.' A particular incident described below soon made it clear that Valcon had to do a much better job in this regard.

One of the first candidates to be hired as a Valcon consultant found himself facing serious problems with the father of his fiancée as a direct result of his appointment. His prospective fatherin-law was now resisting the marriage because he did not consider management consulting to be a decent occupation for his future son-in-law, and because he could not see the value in working for a Scandinavian company instead of a large reputable Indian corporation. This was a wake-up call for Valcon. It forced a rethinking of the way the Valcon story was communicated. As the recruiting partner put it, 'To attract and retain talent we had to re-brand Valcon. The image developed for Scandinavia - the 'how' company helping Scandinavian companies to become global leaders - did not work in India'.

To overcome potentially negative perception issues, Valcon decided to participate in the placement program of one of the elite business schools. All the MBA students there had work experience prior to joining the MBA program and it was therefore a perfect place for a 'how'oriented professional service firm to look for talent. Valcon spent a full day with the students and was asked to give a one-hour lecture in the afternoon. The firm knew it was a wildcard and had to compete for talent with much bigger and better- known global consultancy firms.

For the lecture Valcon built its story around what Scandinavia as a region is well known for around the world - namely the ability to innovate. With fewer than 18 million inhabitants the region has been able to develop a relatively large number of companies that are world leaders in their field. It is the story of a small home market being a good incubator for innovation, but also carries a message about how this situation forces companies to develop services that have a global relevance 
if they want scale and growth. The central idea running through the lecture was that the Scandinavia innovation model has a lot to offer to other parts of the world, and that India as a country could benefit from adopting some of the findings to further boost India as an export-oriented economy. Valcon went on to talk about how innovation is managed in Scandinavia, and used the Valcon story as an example of innovation in the professional services sector. Reflecting on the session, the Valcon partner recalls:

'We communicated how we contribute something new, and how we add value to our clients. We also shared how we have developed a very flat organisation and a compensation system driven by results rather than titles and roles in the company. Furthermore, we talked about how we stimulate innovation within our own service offering and how consultants are involved in the processes'.

In putting these messages across, Valcon was able to convey what makes a Scandinavian management consulting firm different from a USA-based or UK-based professional services firm. The lecture was a success. Valcon enjoyed a highly interactive session with the students and received very positive feedback suggesting that the firm had outperformed many of the big consultancy firms in both content and message. Subsequently Valcon received applications from half of the students as well as from students who had not participated in the lecture but who had heard about it afterward. In the process of learning how best to attract and recruit Indian talent, Valcon arrived at a successful strategy for hiring talented and highly qualified consultants. This 'coming of age' experience also significantly influenced the culture and identity of Valcon as a consulting firm - i.e. Valcon learned, changed and matured as a consequence. Starting up in India was no simple feat for a Scandinavian consulting firm whose standard recruitment strategy is to hire experts with both industry-specific and consulting experience. Compared with its position in the Scandinavian market, Valcon had neither brand profile in India, nor any references from clients with significant brands in 
the country. Furthermore, the firm was competing for talent in a context where the status of the profession and of the employer is far more important than in a Scandinavian context - not least because status plays a crucial role in relation to family acceptance.

The encounter in India was beginning to change the organisational identity and culture of Valcon, reversing the stereotypical process of internationalisation as one-way exporting of Western products, knowledge and ideas (Immelt et al., 2009). As will become increasingly clear in the sections to follow, a new Valcon emerged from this experience: a firm that is not only more international but which is also becoming more clearly differentiated and differently positioned, in the Scandinavian consulting market. Its leaders too, within specialisations such as Lean, are now just as likely to be found at Valcon's Indian subsidiary as at the firm's Danish head office. In terms of ‘frames' of internationalisation, elements of a geocentric orientation (Pearlmutter, 1969) were increasingly evolving, although with a different flair. As emphasised in the Uppsala framework (Johanson and Wiedersheim-Paul, 1975; Johanson and Vahlne, 1977), internationalisation is a process of learning and this first big leap into India has enabled Valcon to move on to China, for example.

\section{3 'Valconising' the Indian consultants - from integration to convergence}

As the process of setting up in India continued, a key question was how to manage the integration of the newly recruited consultants in India. Valcon had a standard introduction program for new employees, which was designed for consultants recruited in Denmark. It included some sessions where partners in Valcon communicated the values that the firm is based on and 'how we work'. It was doubtful that this program on its own would be sufficient for the new Indian colleagues. The same applied to Valcon's standard collaborative tools, which were designed to enable sharing of knowledge between consultants. 
Valcon's chairman suggested that the introduction process should be rethought with respect to India, and it was decided that more of the partners' time should be invested in the integration process. India is far removed from Scandinavia, and not just in terms of physical distance. To do business in India Valcon had to invest in understanding the business culture and mindset. When the first two consultants recruited in India visited Denmark for the first time they did not stay in a hotel. They were invited to stay in the private homes of Valcon's top management. As the overseeing partner comments:

'The purpose was obvious. We wanted to form stronger personal bonds with our new Indian colleagues. We wanted to establish a strong personal connection between them and the partners in Valcon. This kind of personal engagement as part of the integration was very different from anything we had done before’.

In this way Valcon attempted to compensate for the lack of geographical proximity with personal proximity. The firm wanted to be sure that its Indian colleagues felt confident and comfortable with at least one or two partners in Valcon:

'We wanted our Indian consultants to feel comfortable calling us at any time to ask for information or advice. We applied this approach $100 \%$ and involved our families in the integration process. We did not take them out to dinner - we always dined in our private homes. In some cases we even involved our Indian colleagues in the preparation of dinner'.

This arrangement allowed a lot of time for talking and listening. Valcon's partners learned a lot and so did the new consultants. The Indian consultants for their part were not used to this kind of personal proximity in business life. They had all worked for large US, European or Japanese corporations. They were used to a hierarchical organisational set-up where employees do not mingle privately with their superiors, rather than the extremely flat structure that Valcon is based on. 
Suddenly the new recruits found themselves in a new company and being invited to stay at the chairman’s house. Their reactions were generally positive and they were very happy with this introduction to Valcon and to Denmark, even though the experience was quite overwhelming for some of them given their cultural heritage.

What started out as an experiment has now become a new Valcon standard. All new Valcon consultants in India are invited to the private homes of partners at the firm. The only adjustment is that the Indian colleagues are now given the option of hotel accommodation. Expecting them to stay in the private homes of one of the partners was probably taking it a step too far, as it might be too overwhelming for some. There was also the question of whether Valcon would have enough 'integration capacity’ as the firm’s presence in India grew. Valcon believed it was possible however, and in fact several of the Danish Valcon consultants and business unit managers have since offered to take part in the integration process.

At Valcon, the integration of the new employees in India is considered to be extremely successful. In the interview, the managing director of Valcon described the extent to which the consultants in India are Valcon. 'They do not think of 'Valcon India, but of Valcon as a whole. Actually much more than most of our other offices', he reports. Despite the successful integration of the new consultants, Valcon faces a number of challenges in its daily operations in India. Knowledge-sharing between Scandinavia and India in particular is an ongoing challenge due to the fact that most of the existing project documentation in Valcon is in Danish. Translation of the entire knowledge database would be a huge task and require substantial investment. However the good personal networks built up through the integration process have proven to be a good starting point for tackling these challenges. Even so the language challenge remains an obstacle in other ways, making it more difficult to use Indian consultants on Scandinavian projects for example.

Looking back at Valcon’s efforts to embrace new Indian employees into the firm’s established culture and mindset, it is interesting to observe that the decision to create a very close 
personal encounter between the top people in Valcon and the new consultants in India, has had a range of direct consequences. Firstly, it had a strong and lasting effect on the new consultants. Although it was almost too much of a step for some, the gesture secured an important foundation for a close working relationship between the firm's headquarters and its far-flung subsidiary. Secondly, this process of proactive integration not only affected the Indian employees, it also further contributed to the evolution of Valcon's core culture. Although the idea of having new employees stay at the private homes of top management was inspired by the existing values of Valcon as a flat organisation, it was at the same time a significant departure from existing practice. In the effort to create a personal experience for the new Indian consultants and demonstrate the essence of a flat organisation, Valcon momentarily 'collapsed' the hierarchy completely, something it would not normally do as far as domestic employees are concerned.

What happened in the process was not just successful integration or 'Valconisation' of the Indian employees. It also created significant learning in Valcon at the highest level - and continues to do so. The integration was bi-directional and in this sense can be seen as a process of convergence. By this we mean a mutual process of cultural change, with both parties moving in the same direction but each taking a different path towards the same common point: a point of convergence where synergy is created and something new can emerge. This theme will be explored in more detail in the following section.

Convergence means that an encounter between cultures changes both parties - but it does not mean that they become the same. Both parties change, but in different ways. A space for a productive and innovative encounter is created where there is potential for convergence, while differences are maintained. Thus a changed Valcon emerged: a firm that is both more international and more 'Valcon' than ever before. This was clearly expressed by the managing director of Valcon during our interview: 
'The move to India has fundamentally changed our organisational culture in Scandinavia.

The global outlook is now much more present in all our service offerings and not just those which are explicitly international in focus'.

As a consequence the firm's positioning in the Scandinavian market vis-à-vis Valcon's competitors has changed:

'Now suddenly we can discuss issues with our clients which before were the sole domains of the large Tier 1 consulting firms'.

Valcon is developing a more distinct identity as an execution-oriented consulting firm, which also has a strategic and global orientation. Although not following Pearlmutter's geocentric approach as such, the approach undertaken did fuel a drive towards developing a geocentric orientation, or in the context of a professional services firm, a one-firm attitude (Maister, 2000). Again we see the significance of internationalisation as a process of learning as emphasised in the Uppsala model, but less following a specific mode of internationalisation as proposed by the Uppsala School or in Johanson and Mattson's network approach.

\section{4 'Reverse innovation' - bringing services developed in India to the Scandinavian market} Valcon believes that Scandinavia has a lot to offer India, but equally that India also has lot to offer Scandinavia. India is the world leader in offshoring of white-collar work. Its ability to take a business process and package it as a product is world class and India is the global thought leader in this respect. The Business Process Outsourcing/Offshoring industry (BPO) is significant in India. Total revenues amount to more than USD 50 billion. The Scandinavian region is not a large BPO market for India. Organisations in Scandinavia are generally not aware of the potential - at least not compared with their US counterparts. The problem is not the large companies. They have identified 
the potential and the Indian BPO companies know how to deal with them. The problem is the small and medium sized enterprises, which are plentiful in Scandinavia. This is a potential threat to the long-term white-collar productivity in Scandinavia.

Valcon decided that it wanted to understand how it works in India and thus became a client of the Indian BPO industry by encapsulating engineering services from one of the leading BPO companies in its offerings. In the process Valcon learned a lot and, in order to take this knowledge further still, decided to develop its own ‘knowledge process outsourcing’ (KPO) product based on its experience in India.

Valcon is one of the leaders in profitability management in Scandinavia and has developed and implemented activity-based costing concepts for more than 100 companies. Valcon sets it up and the clients run it. Valcon realised however that many of its clients had trouble maintaining the system. Valcon could of course sell the same consulting project twice - but why not take the Indian approach and offer to manage the task on behalf of the client? Valcon developed this new service in India in collaboration with one of its Danish clients. At the time of writing, four months later, the new service is up and running.

It could be argued that this example is not a true case of reverse innovation (Immelt et al., 2009). The service inspired by India will be commercialised first in Scandinavia and then in India. That said, truly reversed professional service innovations will appear too - i.e. services developed in India, commercialised in India, followed by Scandinavia. Valcon expects that it will begin with BPO: Valcon has successfully pioneered the introduction of Lean in white-collar services in Scandinavia so one obvious opportunity is to develop a Lean administration service targeting the Indian BPO industry. This product would be developed and commercialised in India and then later commercialised in Scandinavia. In Lean manufacturing, Toyota in Japan has been used as benchmark. In Lean administration it makes sense that the benchmarks in terms of productivity, quality and lead-time would be based on the Indian BPO industry. By bringing the product to 
Scandinavia, Valcon will be able to take Lean administration to the next level. This will allow Valcon's Scandinavian clients to develop and benchmark in relation to world-class performers. This is important for all the processes that are likely not to be offshored because of critical mass, proximity or political reasons (such as processes in government- controlled organisations servicing the Scandinavian citizens and corporations).

Valcon feels certain that reverse innovation will play an increasingly important role in its future consulting services. Scandinavia has a lot to learn from India - and Valcon will play the role as a catalyst. As Valcon's managing director noted during our interview, he now sends as many of his managers as possible on exchange trips to India as part of their leadership development. It is not just the Indian consultants who are sent to Denmark to become 'Valconised'. That the process now goes both ways indicates clearly that elements of an integrated and increasingly geocentric orientation are developing (Pearlmutter, 1969). The simultaneous focus on exporting Valcon’s mindset and approach, coupled with localisation and recruitment of local consultants, are still central aspects of Valcon's internationalisation orientation however.

In this sense both current and future products and concepts developed in India by local consultants are being and could potentially be sold in both the Indian and the Scandinavian markets. As Valcon is continuously changing and developing through the encounter with India, the firm is beginning to find ways of benefiting from the points of convergence between Scandinavian ways of doing business and Indian ways of approaching management. What is particularly striking about this process is that there is nothing predictable or unidirectional about it. Rather it is a dynamic learning process where ideas, influences and inspirations move back and forth, continuously being mixed and transformed. It is as much a case of 'West meeting East' as 'East meeting West', and in the process new management ideas and concepts are emerging which are neither inherently Eastern or Western, but an optimum blend of both. 


\section{Discussion and conclusion}

The experience of Valcon's entry into the Indian consulting market highlights that the venture did not only create a new channel for selling and delivering consulting services in another part of the world. It also impacted the business, organisation and culture of Valcon much more fundamentally than the partners probably expected during the initial planning.

A number of key observations can be drawn from the case study. Firstly, Valcon followed an alternative approach to internationalisation when setting up its operation in India. Traditional practice would have been to establish a new office or establish a joint venture with a local consultancy to ensure the local touch and network (Johanson and Vahlne, 1977, Johanson and Mattson, 1988). Instead, Valcon chose to develop its Indian practice in partnership with a major client. This model ensured a local presence and local relevance, as creating innovation and value for their clients is a key driver for the firm.

Secondly, Valcon had to rethink its 'normal' practice and value proposition in a 'no name and no brand environment' when starting to recruit. Just presenting the consulting firm in the traditional way would probably not have persuaded anyone to sign up, as Valcon didn't have any well-known client references to present, or any convincing consulting story to tell as the target market has no insight into the Scandinavian market. But the trick of re-branding Valcon in a new context produced a winning formula.

Thirdly, Valcon managed the integration process for the new Indian consultants in a nontraditional way. By galvanising the Valcon culture and thereby 'Valconising' the new consultants by having them come to Denmark and staying with the partners - not only bridged the physical distance but also created much closer social ties. This turned out to be a success. Although having been met with some initial resistance when first introduced, ultimately the impact on the induction program was impressive as this new vehicle for integration triggered a new Valcon standard. More 
fundamentally, the move to India has changed the organisational culture of Valcon and given the firm a global outlook rarely found in Tier 2 consulting firms.

Finally, even though Valcon believed it had a lot to offer India, it turned out that India also had a lot to offer Scandinavia. In most cases a consulting firm will distribute its services when internationalising the practice as a part of the economies-of-scale philosophy and as a means of knowledge distribution (Hitt et al., 2006). However, it turned out that some of the new, locally recruited consultants in India had a cutting-edge competence in specific areas which led to the 'export' back to Scandinavia of a new service - for example within the area of profitability management and Lean management. This too is an example of how advanced knowledge can flow, and thereby create a reverse stream of business elsewhere.

The four key observations discussed here lead to an overall conclusion. All of the observations indicate that the impact of the expansion initiative on Valcon has exceeded all expectations - and in a positive and disruptive way. This could be termed 'reverse consulting' in a broad sense, i.e. that the additional value Valcon has gained from its entry into India is related to new business and organisational learning: not just about how to operate in India, but also in Scandinavia. Having a newly established practice abroad and operating from the perspective of 'reverse consulting' adds to the understanding of new, distant ventures and the ways that consulting firms can boost their practice by capitalising on such activities. It could thus be argued that the concept of reverse consulting more usefully describes the globalisation process of professional services firms, since these are knowledge-intensive and human-capital-based organisations where the essence of the offering resides within the professionals employed; this makes models easier to reverse compared with more capital-intensive industries.

Another conclusion is related to the process of internationalisation and the typical frameworks that have been held up as workable models before now. As we have seen, Valcon's internationalisation process cannot be fully captured by the traditional internationalisation models 
outlined in this paper - such as the Uppsala School (Johanson and Wiedersheim-Paul, 1975; Johanson and Vahlne, 1977), the network approach (Johanson and Mattson, 1988) or the 'born global’ model (McKinsey \& Co, 1993). Rather this example showcases an alternative approach combining 'leapfrogging’ or 'big step’ tactics, where stages in the classical model are skipped (Hedlund and Kverneland, 1985; Pedersen and Shaver, 2011). In Pearlmutter's (1969) terms, we can say that we saw elements of an ethnocentric, polycentric and geocentric orientation. However the case has also illustrated that Valcon did still pursue a familiar model of internationalisation, in being client driven (Rose and Hinings, 1999). We could extrapolate from this that it might suit other professional service firms to subscribe to more of a 'patchwork' orientation when it comes to internationalising their practices, instead of a 'pure' approach.

Our aim in exploring the Valcon's move to India has been to increase our understanding of a relatively unexplored phenomenon. Given that this is a single, exploratory case study, there are obvious limitations to the conclusions drawn. They are specific to one particular Scandinavian consulting firm and contextually dependent. Thus further research needs to be conducted in order to explore whether similar tendencies are also evident in other Tier 2 consulting firms as they expand into different parts of the world. Since there is an increasing trend of management consulting firms internationalising their practices, one challenge is to establish how further research might capture and unravel the concept of reverse consulting both empirically as well as theoretically.

\section{References}

Baden-Fuller, C. (1994) 'The globalization of professional service firms: evidence from four case studies', in Aharoni, Y. (Ed.): Coalitions and Competition - The Globalization of Professional Business Services, Routledge.

Berry, J. (1988) 'Consulting in Europe and the USA: more alike than not’, Journal of Management Consulting, Vol. 4, No. 3. 
Cavusgil, S.T. (1994) 'A quiet revolution in Australian exporters’, Marketing News, Vol. 28, No. 11, pp.18-21.

Consultgenie (2009) Consulting Industry in India, PPT Presentation.

Curnow, B. and Reuvid, J. (Eds) (2001) The International Guide to Management Consultancy, Kogan Page, London, UK.

Frantz, B. and McDougall, G. (2004) 'Assessing the potential of customer relationship management: clarifying the decision’, Services Marketing Quarterly, Vol. 26, No. 1, p.1.

Freeman, S. and Sandwell, M. (2008) 'Professional service firms entering emerging markets: the role of network relationships’, Journal of Services Marketing, Vol. 22, No. 3, pp.198-212.

Greiner, L. and Poulfelt, F. (2009) Management Consulting Today and Tomorrow, Routledge, New York, NY, USA.

Hedlund, G. and Kverneland, A. (1985) ‘Are strategies for foreign markets changing? The case of Swedish invenstment in Japan', International Studies of Management \& Organization, Vol. 15, No. 2, pp.41-59.

Hitt, M., Bierman, L., Uhlenbruck, K. and Shimizu, K. (2006) 'The importance of resource in the internationalization of professional service firms: the good, the bad and the ugly', Academy of Management Journal, Vol. 49, No. 6, pp.1137-1157.

Immelt, J.R., Govindarajan, V. and Trimble, C. (2009) 'How GE is disrupting itself', Harvard Business Review, October.

Jacoby Petersen, N. and Poulfelt, F. (2002) 'Knowledge management in action: a study of knowledge management in management consultancies’, in Bouno, A.F. (Ed.): Knowledge and Value Development in Management Consulting: Research on Consulting Series 1, Information Age Publications Inc., Greenwich, CT, USA.

Jenkins, R. (2004) Social Identity, 2nd ed., Routledge, London, UK. 
Johanson, J. and Mattson, L-G. (1988) 'Internationalization in industrial systems - a network approach’, in Hood, N. and Vahlne, J-E. (Eds): Strategies in Global Competition, Crom Helm, London, UK, pp.287-314.

Johanson, J. and Vahlne, J-E. (1977) 'The internationalization process of the firm - a model of knowledge development and increasing foreign market commitments', Journal of International Business Studies, Vol. 8, No. 1, pp.23-32.

Johanson, J. and Wiedersheim-Paul, F. (1975) 'The internationalization of the firm - four cases', Journal of Management Studies, Vol. 12, No. 3, pp.305-322.

Maister, D. (1985). 'The one-firm firm: what makes it successful?’, MIT Sloan Management Review, Management Consultancy Association, October. Available online at: http://www. mca.org.uk/home

McKenna, C.D. (1995) ‘The origins of modern management consulting’, Business \& Economic History, Vol. 24, No. 1, pp.51-59.

McKinsey \& Co. (1993) Emerging Exporters. Australia’s High Value-Added Manufacturing Exporters, Melbourne, Australia.

Nees, D. (1986) 'Building an international practice', Journal of Management Consulting, Vol. 3, No. 2.

Pearlmutter, H.V. (1969) ‘The tortuous evolution of the multinational corporation’, Columbia Journal of World Business, Vol. 4, No. 1, pp.9-18.

Pedersen, T. and Shaver, J.M. (2011) 'Internationalization revisited: the big step hypothesis’, Global Strategy Journal, Vol. 1, Nos. 3/4, pp.263-274.

Rathore, S. (2010) Consulting in India - The Present and the Future Trends, PPT Presentation. Rogers, P. and Tierney, T. (2004) 'Leadership without control', European Business Journal, Vol. 16, p.78. 
Rose, T. and Hinings, C.R. (1999) 'Global client’s demands driving change in global business advisory firms', in Brock, D.M., Hinings, C.R. and Powell, M.J. (Eds): Restructuring the Professional Organization, Routledge, London, pp.41-67.

Rhinesmith, S. (2009) ‘Globalization consulting’, in Greiner, L. And Poulfelt, F. (Eds): Management Consulting Today and Tomorrow, Routledge, New York, NY, USA. Source Information Services (2011) Management Consulting Market Report, London, UK.

Werr, A. and Stjernberg, T. (2003) 'Exploring management consulting firms as knowledge systems’, Organization Studies, Vol. 24, pp.881-908.

Winch, G.M. (2008) 'Internationalisation strategies in the business-to business services: the case of architectural practice', The Service Industries Journal, Vol. 28, No. 1, pp.1-13.

Yin, R.K. (2003) Case Study Research: Design and Methods, 3rd ed., Applied Social Research Methods Serious, Sage Publications, London, UK, Vol. 5.

Zabala, I., Panadero, G., Gallardo, L.M., Amate, C.M., Saanchez-Galindo, M., Tena, I. and Villaalba, I. (2005) 'Corporate reputation in professional services firms: reputation management based on intellectual capital management', Corporate Reputation Review, Vol. 8, No. 1, pp.59-71. 